\title{
Delayed diagnosis of ingested button battery leading to tracheoesophageal fistula in a child infected with SARS-CoV-2
}

\author{
Pierre Goussard 이 , ${ }^{1}$ Jacques Janson, ${ }^{2}$ Etienne Nel, ${ }^{1}$ Pawel Schubert ${ }^{3}$
}

${ }^{1}$ Paediatrics and Child Health, Stellenbosch University Faculty of Medicine and Health Sciences, Cape Town, South Africa

${ }^{2}$ Cardiothoracic Surgery, Stellenbosch University Faculty of Medicine and Health Sciences, Cape Town, South Africa

${ }^{3}$ Department of Pathology, Division of Anatomical Pathology, Faculty of Medicine and Health Sciences, Stellenbosch University and National Health Laboratory Service, Tygerberg Hospital, Cape Town, South Africa

Correspondence to Professor Pierre Goussard: pgouss@sun.ac.za

Accepted 3 June 2021

Check for updates

(C) BMJ Publishing Group Limited 2021. No commercial re-use. See rights and permissions. Published by BMJ.

To cite: Goussard P, Janson J Nel $\mathrm{E}$, et al. BMJ Case Rep 2021;14:e244544. doi:10.1136/bcr-2021244544

\section{DESCRIPTION}

An 18-month-old baby boy presented with vomiting and dysphagia was admitted to a peripheral hospital. The initial diagnosis was gastroenteritis, and he was treated accordingly. A routine SARS-CoV-2 test was positive, but he did not have any significant respiratory symptoms. However, 5 days after admission, he developed respiratory symptoms with coughing and crepitations audible in his chest and a chest X-ray was performed. This chest X-ray showed a foreign body lodged in the oesophagus, which was suggestive of a button battery with an anterior orientation of the negative pole and distention of the stomach with air (figure 1A,B). The mother was not aware of the ingestion but did recall an episode of choking shortly before admission. The battery was removed under anaesthesia with a rigid oesophagoscope. It was noted that oesophageal tissue adhered to the battery. After removal of the battery, the patient developed severe respiratory distress and abdominal distension. A repeat chest X-ray after removal showed collapse consolidation of the right upper lobe as well as consolidation of the left upper lobe and lingula which was not present before removal, as well as distention of the stomach (figure 1C). $\mathrm{He}$ needed intubation and ventilation. During ventilation, there was an increasing abdominal distension and difficult ventilation with hypercarbia. The patient was transferred by an air ambulance to our service for specialised care. The child required continued ventilatory support and was fed with a nasoduodenal feeding tube (figure $2 \mathrm{~A}$ ). Bronchoscopy and gastroscopy were performed to determine whether an acquired tracheoesophageal fistula (TOF) was present. Bronchoscopy showed a significant number of secretions in both airways and some bubbles originating from behind the endotracheal tube (ET). Gastroscopy confirmed a large fistula between the posterior membrane of the trachea and the oesophagus (video 1A). An area of tissue necrosis was present on the anterior wall of the oesophagus, close to the location of the TOF, and the armoured ET was clearly visible through the fistula (video 1A). If the cuff was inflated, it budged into the airway. The ET was advanced to a position distal to the fistula under direct bronchoscopic vision to reduce the air leak.

The TOF was repaired with a cervical incision about $1 \mathrm{~cm}$ above the supra-sternal notch. The strap muscles were divided centrally, and the trachea was exposed from the cricoid cartilage and mobilised anteriorly along the pretracheal fascia down to the tracheal bifurcation. The trachea was dissected laterally. With the dissection left laterally, an air leak was noticed where the TOF was. A large defect was present in the oesophagus about $1 \mathrm{~cm}$ long. The trachea was opened anteriorly over this area. The communication between the trachea and the oesophagus at the membranous part of the trachea was identified. A tracheal resection was done up until normal membranous trachea, about $1 \mathrm{~cm}$ tracheal resection (video $1 \mathrm{~B}$ ).

The ET was passed through the distal trachea while the proximal and distal segments were mobilised. The defect in the oesophagus was then closed. The proximal and distal ends of the trachea were anastomosed.

Before the anastomoses were closed, the proximal ET tube was passed through the anastomoses after the distal ET tube was removed. One sternothyroid muscle, was mobilised and placed between the trachea and the oesophagus.

The histology sample of the resected trachea showed sections of a tracheal ring with the mucosa being mostly intact with an area showing ulceration with foreign substance in the submucosa and chronic inflammation. On the outside surface, granulation tissue was present. A small loosely lying fragment of squamous epithelium from the oesophagus with inflammation on the adventitial surface was noted.

The child was successfully extubated after surgery, with mild respiratory distress. At extubation, the child was accessed to have normal vocal cord function. He experienced transient swallowing incoordination confirmed by a video fluoroscopic swallow study (VFSS). There was no leak at the site of the anastomosis (figure $2 \mathrm{~B}$ ). He was fed with a nasogastric tube for 2 weeks postsurgery and during this time he was managed by speech and language therapists. A repeat VFSS 2 weeks later demonstrated resolution of the incoordinate swallowing and continued integrity of the TOF repair.

Oral feeds were slowly re-introduced over a period of 1 week.

Repeat bronchoscopy and gastroscopy was done, demonstrating no tracheal stenosis or granulation formation at the site of the surgery (video $1 \mathrm{C}$ ). There were also no oesophageal strictures.

\section{DISCUSSION}

The estimated incidence of button-shaped battery ingestion is 10.5 per million people per year with a case fatality rate of $0.5 \% .^{1}$ The ingestion has been 


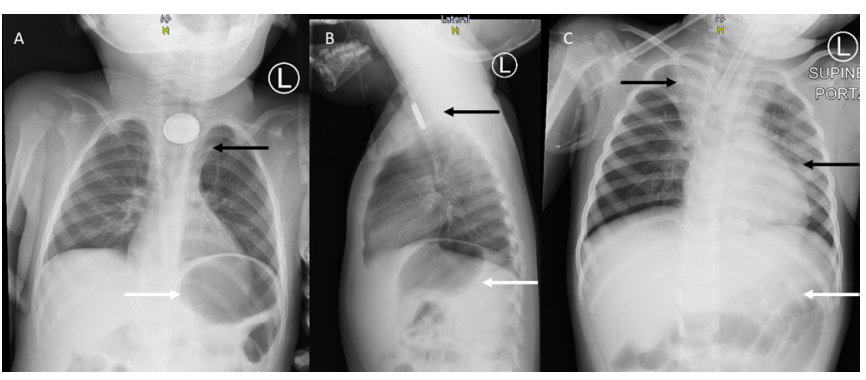

Figure 1 (A) Anterior-posterior chest X-ray demonstrating the button battery (black arrow) in the oesophagus with abdominal distension (white arrow). (B) The lateral confirms the foreign body as a battery with the 'halo sign' and the negative pole directed anteriorly (arrow). (C) Anterior-posterior chest X-ray after the removal showing collapse consolidation of the right upper lobe as well as consolidation of the left upper lobe and lingula (black arrow) with significant distension of the stomach (white arrow).

reported to cause multiple complications, most of these are due to severe oesophageal mucosal injury. The oesophageal injury is caused by the electrolytic production of hydroxides at the negative terminal of the battery which in turn leads to liquefactive tissue necrosis. $^{2}$

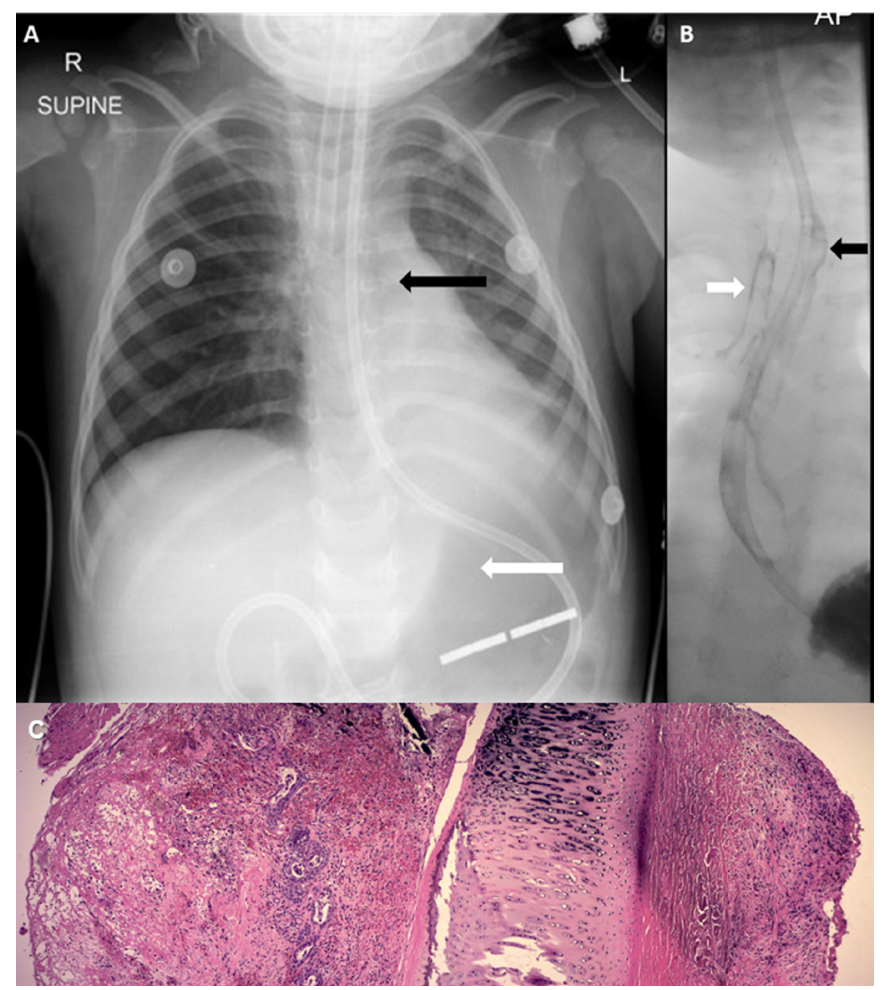

Figure 2 (A and B) Anterior-posterior chest X-ray demonstrating the position of the ET, the duojejunal tube as well as the presence of air in the mediastinum at the tip of the ET (black arrow). Distention of the stomach with air (white arrow). (B) Contrast study demonstrating no leak at the area of repair. The thickening was because the sternothyroid muscle was mobilised and placed between the trachea and the oesophagus (black arrow). The contrast in the trachea and bronchi is due to swallowing incoordination (white arrow). (C) H\&E stain, $4 \times$. Tracheal lumen on left with ulceration, granulation tissue, squamous metaplasia of submucosal glands and a foreign body present just let the cartilage. The adventitia shows mild chronic inflammation. ET, endotracheal tube.

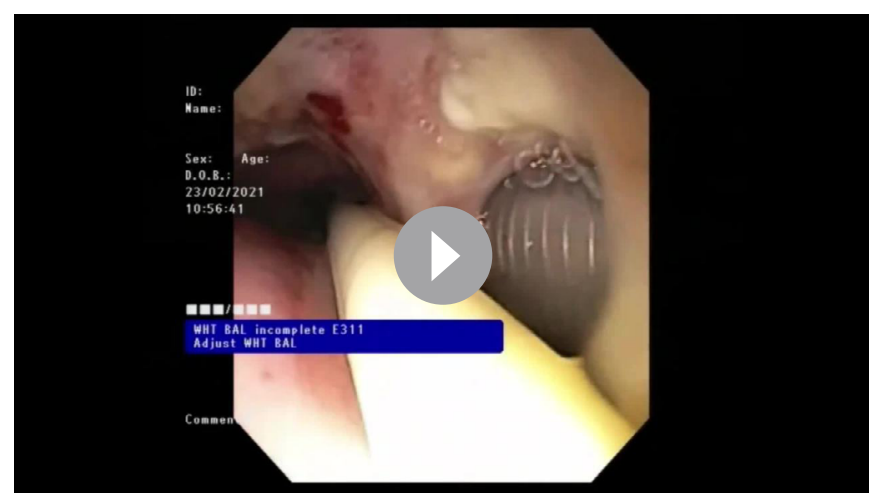

Video 1 (A) Showing the scaring and necrosis of the anterior wall of the oesophagus. Large defect is demonstrated between the oesophagus and the trachea. The armored ET can be seen through the defect in the posterior membrane of the trachea. (B) Demonstrated the surgical repair: surgical view of the cervical incision with the patient's head to the left side of the screen. The ET is in the distal trachea after the trachea was divided at the point where the tracheaesophageal fistula was. The proximal part of the trachea is in the surgeon's left forceps and the right forceps demonstrate the defect in the oesophagus with the nasogastric tube visible. (C) The follow-up bronchoscopy 2 weeks after the repair, with minimal granulation tissue at the tracheal anastomosis. ET, endotracheal tube .

Orientation of the negative terminal of the battery will determine the complications: if it is anterior, the erosion will occur from the oesophagus towards the airway or, if it is orientated posteriorly, erosion into the mediastinum may occur. ${ }^{3}$ Almost all the reported oesophageal impactions were caused from $3 \mathrm{~V}$ (89.5\%), $20 \mathrm{~mm}(81.8 \%)$ lithium-ion batteries. ${ }^{4}$

The most commonly reported complications are oesophageal ulceration, TOF, aorto-oesophageal fistula and pneumonia. ${ }^{1}$ Shaffer et $\mathrm{l}^{4}$ reported that the severe oesophageal complications include the following: stricture $(28.6 \%)$, perforation $(24.5 \%)$, TOF formation $(8.2 \%)$, pneumothorax $(4.1 \%)$ and bilateral true vocal fold paresis (4.1\%).

We describe a young child infected with SARS-CoV-2 with a delayed diagnosis of ingestion of button battery leading to a large acquired TOF after removal. This highlights the dangers of battery ingestion and of late removal. Delayed diagnosis has lead to many complications in this case. Vomiting and respiratory symptoms without diarrhoea may be indicative of oesophageal pathology, requiring further investigation.

\section{Learning points}

SARS-CoV-2 can lead to delay diagnosis in children due to the reduction in routine investigations.

- Major complications of ingestion of button batteries are vocal cord palsies and acquired tracheoesophageal fistula (TOF).

- Removal of button batteries can lead to TOF due to adherence of the battery to the oesophageal wall.

Contributors PG and EN were responsible in the management of the patient. JJ was the surgeon involved. PS was the anatomical pathologist involved.

Funding The authors have not declared a specific grant for this research from any funding agency in the public, commercial or not-for-profit sectors.

Competing interests None declared.

Patient consent for publication Obtained.

Provenance and peer review Not commissioned; externally peer reviewed. 
ORCID iD

Pierre Goussard http://orcid.org/0000-0003-1146-1307

\section{REFERENCES}

1 Eliason MJ, Melzer JM, Winters JR, et al. Identifying predictive factors for long-term complications following button battery impactions: a case series and literature review. Int J Pediatr Otorhinolaryngol 2016;87:198-202.
2 Litovitz T, Whitaker N, Clark L, et al. Emerging battery-ingestion hazard: clinical implications. Pediatrics 2010;125:1168-77.

3 Maves MD, Carithers JS, Birck HG. Esophageal burns secondary to disc battery ingestion. Ann Otol Rhinol Laryngol 1984;93:364-9.

4 Shaffer AD, Jacobs IN, Derkay CS, et al. Management and outcomes of button batteries in the aerodigestive tract: a multi-institutional study. Laryngoscope 2021;131:E298-306.

Copyright 2021 BMJ Publishing Group. All rights reserved. For permission to reuse any of this content visit

https://www.bmj.com/company/products-services/rights-and-licensing/permissions/

BMJ Case Report Fellows may re-use this article for personal use and teaching without any further permission.

Become a Fellow of BMJ Case Reports today and you can:

- Submit as many cases as you like

- Enjoy fast sympathetic peer review and rapid publication of accepted articles

- Access all the published articles

- Re-use any of the published material for personal use and teaching without further permission

\section{Customer Service}

If you have any further queries about your subscription, please contact our customer services team on +44 (0) 2071111105 or via email at support@bmj.com.

Visit casereports.bmj.com for more articles like this and to become a Fellow 